\title{
A PRELIMINARY STUDY ON ESSENTIAL MINERALS IN HUMAN MILK: ASSOCIATION WITH DIETARY HABITS
}

\author{
Liva Aumeistere ${ }^{1,3}$, Inga Ciprovica ${ }^{1}$, Dace Zavadska ${ }^{2}$, Konstantins Bavrins $^{3}$ \\ ${ }^{1}$ Latvia University of Agriculture \\ ${ }^{2}$ Riga Stradins University, Latvia \\ ${ }^{3}$ Institute of Food Safety, Animal Health and Environment BIOR, Latvia \\ liva.aumeistere@bior.lv
}

\begin{abstract}
Human milk provides infant with the required nutrients for growth and development. The aim of preliminary study was to determine macro- and micronutrients content in mature human milk among lactating women residing in Latvia and dietary habits affecting it. The study was carried out from November 2016 to February 2017. In total, 24 pooled diurnal milk samples were collected from mothers whose infants had reached the age of at least two months. Personal information of each participant was recorded, including mother's age, weight and height parameters, sex and age of an infant, parity, breastfeeding pattern, milk expression method used for sampling. Eating habits were obtained using Monthly Food Frequency Questionnaire. Analysed elements were determined using inductively coupled plasma mass spectrometry (ICP-MS Agilent 7700x, Japan). Concentrations ranged from 227.52 to $398.34 \mathrm{mg} \mathrm{L}^{-1}$ for calcium, 58.56 - $256.38 \mathrm{mg} \mathrm{L}^{-1}$ for sodium, $445.33-736.71 \mathrm{mg} \mathrm{L}^{-1}$ for potassium, $25.73-49.52 \mathrm{mg} \mathrm{L}^{-1}$ for magnesium, till $3.17 \mathrm{mg} \mathrm{L}^{-1}$ for iron, $0.28-2.77 \mathrm{mg} \mathrm{L}^{-1}$ for zinc, $0.06-0.43 \mathrm{mg} \mathrm{L}^{-1}$ for copper, $2.00-44.00 \mu \mathrm{g} \mathrm{L}^{-1}$ for manganese, 1.00 $-10.00 \mu \mathrm{g} \mathrm{L}^{-1}$ for chrome which is comparable to data obtained from other studies although chrome and manganese concentration was even higher than observed in literature. Cobalt and selenium content was below detection limit. Zinc content in human milk negatively correlated with baby's age $(p<0.05)$. The content of majority of essential minerals in human milk was affected by mother's dietary habits; however, more samples need to be analysed for representative conclusions.
\end{abstract}

Key words: human milk, essential minerals, dietary habits.

\section{Introduction}

Balanced nutrition supports child's optimal development. Human milk has been recognized as the best food for an infant till six months of age and beyond (WHO, 2009; Motee \& Jeewon, 2014). Breastfeeding mother eating adequate diet should provide offspring with all essential elements (Emmett \& Rogers, 1997). Calcium is a mineral needed for the formation and maintenance of bone mass, as well as for normal function of nerves and muscles. Sodium and potassium support osmotic pressure in cells. Iron is an important element for synthesis of haemoglobin. Chrome potentiates insulin production. Magnesium, copper, selenium, zinc, and manganese are essential co-factors for certain enzymes, therefore needed for numerous biochemical reactions (WHO \& IAEA, 1989; Soetan, Olaiya, \& Oyewole, 2010). Mammary glands regulate concentrations of essential elements in milk to protect infant against deficiencies and excessive amounts (Lönnerdal, 2007, cited by Björklund et al., 2012). A study published jointly by World Health Organization and the International Atomic Energy Agency (WHO \& IAEA, 1989) is still one of the few large-scale studies, used as a reference values for setting adequate daily intakes of minerals for infants. It seems that maternal diet has an effect on mineral composition and content in human milk, however, it depends on which element is being considered (Emmett \& Rogers, 1997; Qian et al., 2010; Choi et al., 2016). There is no data about essential element composition in milk among breastfeeding women living in Latvia; therefore, the aim of preliminary study was to determine macro- and micronutrient content in mature human milk among lactating women residing in Latvia and dietary habits affecting it.

\section{Materials and Methods}

Ethical concerns

The study has obtained approval from the Riga Stradins University Ethic Committee (No. 4/28.7.2016.). Written agreement has been obtained from all the participating women.

\section{Study design}

The study took place from November 2016 to March 2017. Participant group included women from different municipalities of Latvia and babies had to be two months old prior to study. Altogether, 24 pooled diurnal milk samples were obtained. Descriptive characteristics like woman's age, weight and height ratio, sex and age of a baby, parity, breastfeeding manner (exclusive or mixed), milk expression method used during the study (by hand, breast pump or both) were recorded. Monthly Food Frequency Questionnaire (FFQ) - a transformed blank taken from guidelines developed by World Health Organisation (WHO, 2007) was used to assess mother's dietary habits during lactation. Questionnaire included information about the consumption of cereals, meat and their products, fish and shellfish, vegetables, 
fruit, berries, nuts, milk and dairy products, etc. food categories over the past month.

Following five-point scale was used:

- $0=$ ='I never consume this product';

- $1=$ 'I eat it less than once a week';

- $2=$ ='I eat it once a week';

- $3=$ ='two times a week';

- $4=$ ='more than two times a week but not every day';

- $5=$ ='I eat it every day'.

Information about current use of dietary supplements was also collected. Information about participants' financial conditions was not collected although this factor may have an impact on mother's diet during lactation.

\section{Milk sampling and analysis}

Around $100 \mathrm{~mL}$ of pooled diurnal milk was obtained using the most comfortable manner for the mother (hand expression, using breast pump or combining both methods). Participants were asked to express milk from different diurnal periods (including morning, mid-day and evening feeding), however, expression time was not specified (beginning (foremilk) or end of feeding (hindmilk). Information about nursing frequency was not collected. It was also not specified from which breast mothers should express milk (the breast from which baby was suckling or the opposite breast). Samples were stored at $-20^{\circ} \mathrm{C}$ until analysis. Following essential minerals - calcium, chrome, cobalt, copper, iron, magnesium, manganese, potassium, selenium, sodium and zinc were determined using inductively coupled plasma mass spectrometry (ICP-MS Agilent 7700x, Japan).

\section{Statistical analysis}

Analyses were done in duplicate. Data statistical analysis was performed using software IBM SPSS Statistics, version 23.0. The Shapiro-Wilk test was used to evaluate essential element content distribution for normality but due to small sample size nonparametric tests were further used for the analysis of data. Kruskal Wallis test was used to test categorical variables and continues variables were compared using Spearman's rank correlation coefficient (Spearman's r). Spearman's r was also used to analyse how mother's dietary habits affect mineral content in milk $(\alpha=0.05)$.

\section{Results and Discussion}

The women included in the present study on average were $30 \pm 4$ years old. Maternal Body Mass Index was $22.11 \pm 2.75$. It was calculated based on given information about weight and height. Anthropometric measurements were not made during this study. Primiparas were $37 \%$ of participants. Of the babies, $54 \%$ were female but $46 \%$ - male and the average birth weight for infants was $3.54 \pm 0.56 \mathrm{~kg}$. The average age was $4 \pm 2$ months (Table 1 ).

Literature is inconsistent with data for many, especially ultra-trace elements (like cobalt) content in human milk. In addition, differences in sampling and analytical testing should be taken into consideration. Table 2 represents the summarization of our preliminary study results with data from literature. Despite the small sample size, our obtained results were comparable with data given in WHO \& IAEA (1989) study for most elements. Concentrations of iron, manganese, chrome and zinc in milk were normally distributed. Small inter-individual variations $(\mathrm{CV} \leq 17)$ were detected for calcium, potassium, magnesium, complying with data from WHO \& IAEA (1989) survey and indicating that homeostatic mechanisms are involved regarding content of those elements in human milk. Cobalt and selenium content was below detection limit. Comparing to other studies, we obtained higher results for manganese and chrome.

Plenty of elements significantly correlated with each other. Most frequently, sodium positively correlated with calcium (Spearman $r=0.42, p<0.05$ ),

\section{Descriptive characteristics of participants}

\begin{tabular}{|c|c|c|}
\hline Characteristics & \multicolumn{1}{|c|}{ Mean \pm SD } & Range \\
\hline \multicolumn{3}{|c|}{ Maternal characteristics } \\
\hline Age (years) & $30 \pm 4$ & $23-37$ \\
\hline Body Mass Index $\left(\mathrm{kg} \mathrm{m}^{-2}\right)$ & $22.11 \pm 2.75$ & $18.25-28.55$ \\
\hline Parous & $37 \%$ primiparas & $2-11$ \\
\hline \multicolumn{3}{|c|}{ Infant characteristics } \\
\hline Age (months) & \multicolumn{1}{|c|}{$4 \pm 2$} & $2.55-4.70$ \\
\hline Birth weight $(\mathrm{kg})$ & $3.54 \pm 0.56$ & \\
\hline Sex & $54 \%$ female, $46 \%$ male &
\end{tabular}


Table 2

Essential element concentration in human milk as referred in the literature and from current study

\begin{tabular}{|c|c|c|c|c|c|c|}
\hline & Current study & $\begin{array}{c}\text { WHO \& IAEA, } \\
1989\end{array}$ & $\begin{array}{c}\text { Yamawaki et } \\
\text { al., } 2005\end{array}$ & Shi et al., 2011 & $\begin{array}{l}\text { Björklund et al., } \\
2012\end{array}$ & $\begin{array}{c}\text { Andrade et al. } \\
2014\end{array}$ \\
\hline \multicolumn{7}{|c|}{$\mathrm{mg} \mathrm{L}^{-1}$} \\
\hline $\mathrm{K}$ & $445.33-736.71$ & $410.00-550.00$ & $437.33 \pm 7.57$ & $540.00 \pm 146.00$ & $633.00 \pm 40.00$ & n.i. ${ }^{a}$ \\
\hline $\mathrm{Ca}$ & $227.52-398.34$ & $220.00-300.00$ & $249.00 \pm 16.52$ & $334.00 \pm 70.00$ & $305.00 \pm 45.00$ & $142.30 \pm 21.60$ \\
\hline $\mathrm{Na}$ & $58.56-256.38$ & $90.00-130.00$ & $120.67 \pm 16.50$ & n.i. & $217.00 \pm 77$ & n.i. \\
\hline $\mathrm{Mg}$ & $25.73-49.52$ & $29.00-38.00$ & $28.33 \pm 4.16$ & $37.00 \pm 10.00$ & $28.00 \pm 4.80$ & $39.80 \pm 4.20$ \\
\hline $\mathrm{Fe}$ & $\mathrm{BDL}-3.17$ & $0.35-0.72$ & $0.11 \pm 0.07$ & $0.50 \pm 0.20$ & $0.34 \pm 0.13$ & $2.70 \pm 0.40$ \\
\hline $\mathrm{Zn}$ & $0.28-2.77$ & $0.70-2.00$ & $0.10 \pm 0.06$ & $2.00 \pm 1.00$ & $3.47 \pm 0.98$ & $3.60 \pm 0.20$ \\
\hline $\mathrm{Cu}$ & $0.06-0.43$ & $0.18-0.31$ & $0.03 \pm 0.01$ & $0.04 \pm 0.02$ & $0.47 \pm 0.08$ & $0.40 \pm 0.02$ \\
\hline \multicolumn{7}{|c|}{$\mu \mathrm{g} \mathrm{L}^{-1}$} \\
\hline $\mathrm{Mn}$ & $2.00-44.00$ & $3.00-4.00$ & $0.97 \pm 0.21$ & n.i. & $3.00 \pm 1.40$ & n.i. \\
\hline $\mathrm{Cr}$ & $1.00-10.00$ & $0.80-1.50$ & $5.03 \pm 2.55$ & n.i. & $0.30 \pm 0.27$ & n.i. \\
\hline $\mathrm{Se}$ & BDL & $13.00-24.00$ & $1.53 \pm 0.25$ & $1.50 \pm 0.60$ & $13.00 \pm 2.6$ & n.i. \\
\hline $\mathrm{Co}$ & $\mathrm{BDL}^{\mathrm{b}}$ & $0.15-0.35$ & n.i. & n.i. & $0.0059 \pm 0.050$ & n.i. \\
\hline
\end{tabular}

${ }^{a}$ No information

${ }^{\mathrm{b}}$ Below detection limit

iron $(\mathrm{r}=0.56, \mathrm{p}<0.01)$ and potassium $(\mathrm{r}=0.56$ $\mathrm{p}<0.01)$ content. This is opposite to Björklund et al. (2012) research where a negative correlation between sodium and potassium content in milk was observed $(\mathrm{r}=-0.39, \mathrm{p}<0.01)$. Carrying on with our study, also manganese correlated with three other elements potassium $(\mathrm{r}=-0.42, \mathrm{p}<0.05)$, magnesium $(\mathrm{r}=-0.41$, $\mathrm{p}<0.05)$ and iron $(\mathrm{r}=0.48, \mathrm{p}<0.05)$. Magnesium content positively correlated with potassium $(\mathrm{r}=0.45$, $\mathrm{p}<0.05)$ but chrome negatively with zinc $(\mathrm{r}=-0.45$, $\mathrm{p}<0.05$ ) content.

Cobalt and selenium content in analysed samples were below detection limit. It is difficult to evaluate what influences cobalt content in human milk because only few studies have data about this trace mineral (WHO \& IAEA, 1989; Björklund et al., 2012). Several studies indicate that selenium content in human milk is affected by mother's diet (Emmett \& Rogers, 1997; Zachara \& Pilecki, 2000). It should be emphasized that critically low selenium content in milk among lactating women residing in Latvia could be due to the fact that Latvia belongs to countries with a low selenium level in the soil and hence the food supply (Duma et al., 2011) but further investigations are needed.

\section{Maternal characteristics}

Arnaud and Favier (1995, cited by Choi et al., 2016) reported that the concentration of copper in human milk is related to parity $(\mathrm{r}=0.317, \mathrm{p}<0.001)$ and mother's Body Mass Index (BMI) $(r=0.324$, $\mathrm{p}<0.001)$. Our preliminary results did not show any correlation between essential elements' content in milk and maternal BMI or parity $(\mathrm{p}>0.05)$. However, more samples need to be analysed and potentially anthropometric measurements need to be included in the research.

\section{Infant characteristics}

There are three stages of lactation - colostrum, transitional and mature milk. Yamawaki et al. (2005) observed decrease for sodium and potassium content in milk comparing day $1-5$ (colostrum) to day 165 - 181 of lactation (mature milk). Richards with co-authors (2010) observed that sodium content decreases during lactation period, reaching reduction of $33 \%$ over the first six months post partum. Similarly, Shi and co-authors (2011) observed that most minerals (except for sodium and potassium) in human milk remain fairly constant over the three lactation stages. In our preliminary study, babies had to be at least two months old, therefore only mature milk samples were analysed. Overall, infants were two to eleven months old and we could not demonstrate a correlation between mineral content in human milk and offspring's age, except for zinc $(\mathrm{r}=-0.528, \mathrm{p}<0.01)$. However, more samples need to be analysed to evaluate observed association.

There is evidence that infant's gender and birthweight can affect macronutrient like fat and lactose content in human milk (Altufaily, 2009; Broka et al., 2016) but no similar observations in any research had been made regarding essential elements content. In addition, our data marked a tendency 
Food consumption frequency points among participants

\begin{tabular}{|c|c|c|c|}
\hline Foodstuff & Median & Minimum & Maximum \\
\hline Cereals \& cereal products & 1.0 & 0 & 5 \\
\hline Bread & 3.0 & 0 & 5 \\
\hline Eggs & 3.0 & 0 & 5 \\
\hline Meat \& meat products & 2.0 & 0 & 4 \\
\hline Fish \& shellfish & 1.0 & 0 & 4 \\
\hline Milk & 5.0 & 0 & 5 \\
\hline Dairy products & 2.0 & 0 & 5 \\
\hline Fresh vegetables & 3.0 & 0 & 5 \\
\hline Cooked vegetables & 2.0 & 0 & 5 \\
\hline Legumes & 1.0 & 0 & 3 \\
\hline Soups & 2.0 & 0 & 4 \\
\hline Fresh fruits \& berries & 3.0 & 0 & 5 \\
\hline Dried fruit \& berries & 1.0 & 0 & 5 \\
\hline Nuts & 1.5 & 0 & 5 \\
\hline Seeds & 1.0 & 0 & 5 \\
\hline Butter & 3.0 & 0 & 5 \\
\hline Vegetable oils (Helianthus annuus, Olea europaea oil, etc.) & 4.0 & 1 & 5 \\
\hline Sauces \& condiments & 1.0 & 0 & 5 \\
\hline Sweets \& sugary snacks & 1.0 & 0 & 5 \\
\hline Fast food (pizza, hot dogs, etc.) & 1.0 & 0 & 2 \\
\hline Salty snacks (chips, salted nuts) & 1.0 & 0 & 2 \\
\hline Vegetable or fruit juices & 0.0 & 0 & 5 \\
\hline Sugary drinks & 0.0 & 0 & 1 \\
\hline Coffee & 5.0 & 0 & 5 \\
\hline $\begin{array}{l}\text { Other caffeine containing drinks } \\
\text { (cappuccino, latte, hot chocolate) }\end{array}$ & 2.0 & 0 & 5 \\
\hline Caffeine containing tea (green, black, etc.) & 2.5 & 0 & 5 \\
\hline Herbal tea (Mint (Mentha piperita), Chamomile (Matricaria recutita), etc.) & 5.0 & 0 & 5 \\
\hline Alcohol & 0.0 & 0 & 3 \\
\hline
\end{tabular}

that infant's birth weight or sex has no influence on mineral content in mature human milk $(\mathrm{p}>0.05)$. However, more participants need to be acquired for representative conclusions.

\section{Diet}

Clustered foodstuff consumption frequencies are displayed in Table 3.

Most mothers consumed one or few dietary supplements during the participation in the study vitamin $D(n=5)$, iron supplement $(n=4)$, omega fatty acids $(n=3)$ and complex supplements $(n=4)$ or functional products like pollen $(\mathrm{n}=1)$, mineral water $(n=2)$, spirulina $(n=1)$ or molasses $(n=1)$ which could also be a source of minerals. Although Choi et al. (2016) observed that mothers who took daily supplements had higher iron concentration in milk, no similarity was observed in this study $(\mathrm{p}>0.05)$.

Iron and zinc concentration in human milk is comparatively low, but their absorption is high (WHO, 2009). Although meat and offals are better dietary source of iron, dark green leafy vegetables and molasses also contribute to intake of this microelement (Soetan, Olaiya, \& Oyewole, 2010). Our data from Food Frequency Questionnaire only unveiled a negative connection with cooked vegetable and soup consumption $(r=-0.49$ and $r=-0.48, p=0.02$ for both, respectively) and iron content in human milk.

Most participating mothers excluded alcoholic beverages from the diet during breastfeeding (67\%) but the rest - restricted consumption to less than once a week $(n=6)$, or 1 to 2 times per week $(n=2)$. Mentioned participants preferred red or white wine. Unit was 
one glass, drunk in the evening, accounting the time between alcohol consumption and breastfeeding. We revealed that zinc content negatively correlates with alcoholic beverage consumption $(\mathrm{r}=-0.42, \mathrm{p}=0.04)$. Choi with co-authors (2016) observed that mothers who consumed alcohol during pregnancy tended to have lower concentration of zinc in milk, as well as less copper and iron content; however, no information about drinking habits during lactation was recorded in mentioned study (Choi et al., 2016). It should be noted that unlike pregnancy, when alcohol is directly passed to fetus, a lactating woman who drinks occasionally can limit exposure to offspring by considering time interval between drinking and breastfeeding (Mennella, 2001).

Our results spotted a correlation between zinc content in milk and dried fruit consumption $(r=0.42$, $\mathrm{p}<0.05)$. Similarly, Leotsinidis with co-authors (2005) observed that fruit consumption was positively associated with zinc level in human milk. In addition, Choi et al. (2016) revealed that intake of meat and meat products positively influenced zinc content.

Sodium intake in infancy may have an effect on blood pressure in later life (Geleijnse et al., 1997). Our study revealed a negative correlation between fresh and dried fruit as well as different seed consumption $(\mathrm{r}=-0.42,-0.47$ and -0.59 , respectively; $\mathrm{p}<0.05)$. This maybe could be explained by the fact that fruit, especially dried fruit, are a rich source of potassium. Human milk has to be isomolar with plasma, but potassium \& sodium has an antagonistic function, contributing to osmolar load (Richards et al., 2010).

According to our preliminary data, potassium content in milk only correlated with seed (linseed (Linum usitatissimum), sesame seeds (Sesamum indicum), etc. seeds) consumption $(\mathrm{r}=-0.41, \mathrm{p}<0.05)$.

Research done by Dagnelie and co-authors (1992) revealed that magnesium content in human milk was positively associated with meat and fish consumption. However, our study marked a tendency that magnesium concentration in mature human milk correlates with plant based product consumption. We observed a correlation between magnesium and wholemeal pasta $(\mathrm{r}=0.55, \mathrm{p}=0.01)$ and dried berries $(\mathrm{r}=0.43, \mathrm{p}=$ 0.03 ) consumption. Magnesium concentration also negatively correlated with caffeine containing drink like cappuccino, latte and hot chocolate $(\mathrm{r}=-0.49, \mathrm{p}$ $=0.02$ ).

Our results marked a tendency that chrome content in mature human milk correlates with shellfish $(\mathrm{r}=-0.45, \mathrm{p}=0.03)$, sour cream $(\mathrm{r}=0.54$, $\mathrm{p}=0.01)$ and vegetable oils (Helianthus annuus, Olea europaea oil, etc. vegetable oils) $(\mathrm{r}=0.47$, $\mathrm{p}=0.02$ ) consumption. It is difficult to explain these preliminary observations, and thus more participants need to be acquired.
Manganese content in human milk correlated with several food categories, including animal and plant based products but more data are needed to analyse acquired interconnectedness.

According to our preliminary results, calcium and copper content was not influenced by mother's diet $(p>0.05)$. Dagnelie with co-authors (1992) observed that human milk from macrobiotic mothers contained less calcium. Organically grown cereals, vegetables and pulses are the dominating products in macrobiotic diet. However, also no effect of consumption of animal products on calcium was observed (Dagnelie et al., 1992). Choi with co-authors (2016) observed that daily intake of vitamin $\mathrm{C}$, selenium and iodine were related to copper content in milk. Leotsinidis with co-authors (2005) noticed that fruit consumption was positively associated with copper level in human milk which could be related to the fact that fruit are a good source of vitamins (including, vitamin C).

Nevertheless, further conclusions should be drawn when more milk samples will be analysed.

\section{Breastfeeding pattern}

After six months of age, an infant's nutritional needs start to exceed what is ensured by human milk; therefore, a complementary feeding is started (WHO, 2009). However, breastfeeding still provides many benefits to the infant and mothers are encouraged to continue nursing till the age of 2 years and beyond (WHO, 2009). Most mothers in our preliminary study were still exclusively breastfeeding $(n=17)$, six participants had started weaning but one mother was combining breastfeeding with the use of infant formula. Results revealed that breastfeeding pattern does not influence essential mineral content in human milk $(\mathrm{p}>0.05$ ), but more participants need to be acquired for further observations.

\section{Milk expression method}

Participants were allowed to use the mostconvenient method for milk expression - by hand (29\%), using breast pump $(63 \%)$ or both techniques $(8 \%)$. Milk composition can be affected by the use of breast pump because water evaporates during the process (Morton et al., 2009; Miller et al., 2013). However, we did not observe that milk expression manner impacts essential element composition in human milk $(\mathrm{p}>$ 0.05). Participants were asked to express milk from different diurnal periods (including morning, mid-day and evening feeding); however, expression time was not specified (beginning (foremilk) or end of feeding (hindmilk). Information about nursing frequency was not collected. It was also not specified from which breast mothers should express milk (the breast from which baby was suckling or the opposite breast). All the above mentioned incompleteness also could 
influence the results we obtained in our preliminary study. Certainly, more samples are needed for further conclusions and continuing the research, sampling process should be more specified.

\section{Conclusions}

Preliminary results revealed that content of most elements (calcium, sodium, potassium, magnesium, iron, zinc and copper) in mature milk among respondents is comparable to data found in literature. Higher concentrations than observed from other studies were found for manganese and chrome, but lower - for cobalt and selenium. Our obtained results also marked a tendency that zinc content in mature human milk correlates negatively with baby's age. Mother's eating habits possibly influence majority of essential elements' content in human milk, but more data need to be obtained for representative conclusions. Continuing the research, sampling process should also be more specified.

\section{Acknowledgment}

Research was funded by grant from the programme 'Strengthening Research Capacity in the Latvia University of Agriculture'. Contract No. 3.2.-10/44. We are grateful to all the women who took part in the study and donated milk samples.

\section{References}

1. Altufaily, Y.A. (2009). The effect of infant gender on the quality of breast milk. Kufa Med. Journal 12(1), $435-440$.

2. Andrade, M.T.S., Del Ciampo, L.A., Del Ciampo, I.R.L., Ferraz I.S., \& Barbosa Junior, F. (2014). Breast Milk Micronutrients in Lactating Mothers from Ribeirão Preto (SP), Brazil. Food Nutr. Sci. 5, 1196 - 1201. DOI: 10.4236/fns.2014.513130.

3. Björklund, K.L., Vahter, M., Palm, B., Grandér, M., Lignell, S., \& Berglund, M. (2012). Metals and trace element concentrations in breast milk of first time healthy mothers: a biological monitoring study. Environ. Health. 11(92). DOI: 10.1186/1476-069X-11-92.

4. Broka, L., Daugule, I., Ciproviča, I., Kviḷūna, D., \& Rumba-Rozenfelde, I. (2016). Comparison of Breast Milk Composition Among Lactating Woman in Latvia. Proc. Latvian Acad. Sci., Section B. 70(2), 47 - 50. DOI: 10.1515/prolas-2016-0009.

5. Choi, Y.K., Kim, J.M., Lee, J.E., Cho, M.S., Kang, B.S., Choi, H., \& Kim, Y. (2016). Association of Maternal Diet With Zinc, Copper, and Iron Concentrations in Transitional Human Milk Produced by Korean Mothers. Clin. Nutr. Res. 5(1), 15 - 25. DOI: 10.7762/cnr.2016.5.1.15.

6. Dagnelie, P.C., van Staveren, W.A., Roos, A.H., Tuinstra, L.G.M.Th., \& Burema, J. (1992). Nutrients and contaminants in human milk from mothers on omnivorous diets. Eur. J. Clin. Nutr. 46, 355 - 366.

7. Duma, M., Alsina, I., Dubova, L., Stroksa, L., \& Smiltina, Z. (2011). The Effect of Sodium Selenite and Selenate on the Quality of Lettuce. In $6^{\text {th }}$ Baltic Conference on Food Science and Technology 'Innovations for Food Science and Production' 'FOODBALT-2011', 5 - 6 May 2011 (pp. 39 - 44). Riga, Latvia: 'Drukātava'.

8. Emmett, P.M., \& Rogers, I.S. (1997). Properties of human milk and their relationship with maternal nutrition. Early Hum. Dev. 49, S7 - S28. DOI: 10.1016/S0378-3782(97)00051-0.

9. Geleijnse, J.M., Hofman, A., Witteman, J.C.M., Hazebroek, A.A.J.M., Valkenburg, H.A., \& Grobbee, D.E. (1997). Long-term Effects of Neonatal Sodium Restriction on Blood Pressure. Hypertension. 29, 913 917. DOI: 10.1161/01.HYP.29.4.913.

10. Leotsinidis, M., Alexopoulos, A., \& Kostopoulou-Farri, E. (2005). Toxic and essential trace elements in human milk from Greek lactating women: Association with dietary habits and other factors. Chemosphere. 61(2), 238 - 247. DOI: 10.1016/j.chemosphere.2005.01.084.

11. Mennella, J. (2001). Alcohol's Effect on Lactation. Alcohol Res. Health. 25(3), 230 - 234.

12. Miller, E.M., Aiello, M.O., Fujita, M., Hinde, K., Milligan, L., \& Quinn E.A. (2013). Field and Laboratory Methods in Human Milk Research. Am. J. Hum. Biol. 25(1), 1 - 11. DOI: 10.1002/ajhb.22334.

13. Morton, J., Hall, J.Y., Wong, R.J., Thairu, L., Benitz, W.E., \& Rhine, W.D. (2009). Combining hand techniques with electric pumping increases milk production in mothers of preterm infants. J. Perinatol. 29(11), 757 - 764. DOI: 10.1038/jp.2009.87.

14. Motee, A., \& Jeewon, R. (2014). Importance of Exclusive Breast Feeding and Complementary Feeding among Infants. Curr. Res. Nutr. Food Sci. Jour. 2(2), 56 - 72. DOI: 10.12944/CRNFSJ.2.2.02.

15. Qian, J., Chen, T., Lu, W., Wu, S., \& Zhu, J. (2010). Breast milk macro-and micronutrient composition in lactating mothers from suburban and urban Shanghai. J. Paediatr. Child Health. 46, 115 - 120. DOI: 10.1111/j.1440-1754.2009.01648.x. 
16. Richards, A.A., Darboe, M.K., Tilling, K., Smith, G.D., Prentice, A.M., \& Lawlor, D.A. (2010). Breast milk sodium content in rural Gambian women: between and within-women variation in the first 6 months after delivery. Paediatr. Perinat. Epidemiol. 24, 255 - 261. DOI: 10.1111/j.1365-3016.2010.01111.x.

17. Shi, Y.D., Sun, G.Q., Zhang, Z.G., Deng, X., Kang, X.H., Liu, Z.D., Ma, Y., \& Sheng, Q.H. (2011). The chemical composition of human milk from Inner Mongolia of China. Food Chem. 127, 1193 - 1198. DOI: 10.1016/j.foodchem.2011.01.123.

18. Soetan, K.O., Olaiya, C.O., \& Oyewole, O.E. (2010). The importance of mineral elements for humans, domestic animals and plants: A review. Afr. J. Food Sci. 4(5), $200-222$.

19. Yamawaki, N., Yamada, M., Kan-no, T., Kojima, T., Kaneko, T., \& Yonekubo, A. (2005). Macronutrient, mineral and trace element composition of breast milk from Japanese women. J. Trace Elem. Med. Biol. 19, 171 - 181. DOI: 10.1016/j.jtemb.2005.05.001.

20. World Health Organisation (WHO), \& International Atomic Energy Agency (IAEA). (1989). Minor and Trace Elements in Breast Milk. Retrieved March 12, 2017, from: http://apps.who.int/iris/ bitstream/10665/39678/1/9241561211.pdf.

21. World Health Organisation (WHO). (2007). Fourth WHO Coordinated Survey of Human Milkfor Persistent Organic Pollutants in Cooperation with UNEP. Guidelines for Developing a National Protocol. Retrieved March 10, 2017, from: http://www.who.int/foodsafety/chem/POPprotocol.pdf.

22. World Health Organization (WHO). (2009). Infant and young child feeding: model chapter for textbooks for medical students and allied health professionals. Retrieved March 11, 2017, from: http://apps.who.int/ iris/bitstream/10665/44117/1/9789241597494_eng.pdf.

23. Zachara, B.A., \& Pilecki, A. (2000). Selenium Concentration in the Milk of Breast-Feeding Mothers and Its Geographic Distribution. Environ. Health. Perspect. 108(11), 1043 - 1046. 